\title{
Imigrantes africanos solicitantes de refúgio na indústria avícola halal brasileira
}

\author{
Allan Rodrigo de Campos Silva*
}

\begin{abstract}
Diante da lei está um porteiro. Um homem do campo dirige-se a este porteiro e pede para entrar na lei. Mas o porteiro diz que agora não pode permitir-lhe a entrada. $O$ homem do campo reflete e depois pergunta se então não pode entrar mais tarde. "É possivel", diz o porteiro, "mas agora não". - O processo, Franz Kafka.
\end{abstract}

\section{O processo de pesquisa}

Em setembro de 2008, um grupo de estudantes de Geografia da Universidade de Innsbruck, da Áustria, realizou, com a ajuda do Professor Heinz Dieter Heidemann, da Universidade de São Paulo, um trabalho de campo temático sobre migrações em São Paulo do qual participei como monitor. 0 roteiro, que começava na Rua Maria Antonia, propunha uma caminhada em torno do centro da cidade, em direção à Baixada do Glicério - porção da cidade localizada a poucos metros da Praça da Sé - onde se localiza a Casa do Migrante e a sede desta mesma Revista Travessia. Durante a caminhada pelo Brás, entre uma Casa do Norte e uma Cantina, nos deparávamos com grupos de imigrantes africanos pelas esquinas. A própria Casa do Migrante encontrava-se em meio a uma inflexão de público, então majoritariamente composto por imigrantes africanos. Fiz dessa experiência o ponto de partida

\footnotetext{
* Geógrafo, doutorando no Programa de Pós-Gradução em Geografia Humana da Universidade de São Paulo.
} 
para uma pesquisa que se desenrola desde então. Ao mesmo tempo, a participação em grupos de estudo no Laboratório de Geografia Urbana da USP ventilou ideias e sugeriu pistas para seguir a caminhada.

Logo, a Casa do Migrante se tornou uma referência de pesquisa importante. Nas primeiras visitas travei contato com um grupo de imigrantes, ainda que diversas dificuldades se apresentassem. Carla, assistente social e Dirceu, editor da revista, já haviam me apresentado um diagnóstico básico da situação e das trajetórias dos albergados, informações que ajudaram a criar um cenário inicial. Foi então que, numa caminhada pelo pátio interno da Casa, com uma prancheta embaixo do braço, comecei a fazer algumas perguntas sobre a origem de alguns jovens sentados no banco central. Mesmo com o ambiente acolhedor da Casa, a situação de desamparo geral dos imigrantes dificultava a conversa, mas logo que a conversa deslanchava, muitos se sentiam movidos a dividirem suas experiências e traumas, além de explicitar a ignorância do pesquisador em relação aos contextos que os haviam mobilizado na África.

Uma proximidade pessoal foi se desenvolvendo entre mim e um grupo de quatro jovens, entre 21 e 23 anos de idade, da Guiné (Conakri) e um nigeriano de 32 anos de idade. Essa proximidade possibilitou, por um lado, executar o trabalho de pesquisa que em parte apresentaremos aqui. Por outro lado, o convívio com esse grupo aos poucos explicitou a contradição da relação que um pesquisador estabelece com seu "objeto de estudo": a reificação, posta na relação entre pesquisador e pesquisado, se amarra a determinações mais profundas - um momento da forma social moderna da mercadoria. Tais determinações fazem com que os termos da relação entre pesquisador e pesquisado, ainda que se tente humanizar a relação ou destacar sua subjetividade, sejam novamente momentos de reprodução da sociedade produtora de mercadorias.

\section{Diante do trabalho: o sangrador de frangos halal}

Ao longo de 2009, a relação continuada com este grupo de imigrantes, - Basil I., Abdul H., Fadi B, Hamal A., da Guiné e Mahdi M., da Nigéria, permitiu desdobrar o processo de pesquisa. Os cinco rapazes logo encontraram um bico na construção civil: trabalharam como serventes de pedreiro em um prédio residencial no município de Mauá, por 15 reais a diária. Sustentaram isso por duas semanas, até que B. consegui um contato na Mesquita do Brás que ofereceu ao grupo um trabalho como sangrador de frangos para o Grupo de Abate Halal (GAH), uma empreiteira que certifica a produção de carnes exportadas para o mundo islâmico pelos maiores frigoríficos do Brasil, como Sadia, Perdigão e Seara. Para que a carne seja certificada como halal, ou seja, permitida ao consumo do muçulmano, o sangrador precisa ser homem e muçulmano. Logo I., H., B e A. viajaram para Francisco Beltrão, no oeste paranaense, com contratos temporários assinados em São Bernardo do Campo, na sede da GAH, para trabalharem como sangradores de frango na planta da Sadia, por um salário de 800 reais por mês. 
Enquanto isso M. continuava a procurar um emprego em São Paulo. M. é um jogador de Futebol de 32 anos, que havia saído da Nigéria em 2003 em direção à Trinidad e Tobago, onde morou e jogou futebol por cinco anos. Quando o Brasil foi anunciado como sede dos Jogos Olímpicos e da Copa do Mundo, M. vislumbrou a possibilidade de se envolver profissionalmente em tais eventos. Entretanto, a difícil estada de quatro meses e meio em São Paulo, sem encontrar nem o eco de uma oportunidade de trabalho no setor de esportes, logo o expulsou da cidade. Com uma passagem para Manaus garantida, M. escapou para a Venezuela de carona e voltou a trabalhar em Trinidad e Tobago.

Meu contato com os jovens da Guiné se reduziu a poucas trocas de e-mails até maio de 2011, quando realizei um trabalho de campo em Francisco Beltrão, na vigência de uma bolsa de pesquisa de mestrado da FAPESP. Nesta época I. já havia se mudado para Uberlândia, realocado na rede de sangradores do GAH. I. é negro e pertence a etnia Fulani e em diversas conversas já havia relatado como o racismo havia sido definitivo na sua decisão de migrar para o Brasil. A Guiné vivia então o momento auge de um conflito social amplo que se apresentava mais imediatamente como conflito étnico. Desde que um presidente de outra etnia assumiu o poder, as pessoas da etnia Fulani passaram a ser declaradamente perseguidas nas ruas e dentro de suas casas. Sua família inteira havia sido executada na sua frente. Depois disso, com a ajuda de um primo, que acessou um dinheiro do partido Fulani, comprou uma passagem de avião para Guarulhos. Os quatro guineenses se conheceram na salinha da polícia federal do aeroporto de Cumbica e então se tornaram companheiros e viveram por quase dois anos juntos em Francisco Beltrão. I. reclamava constantemente do tratamento que recebia no Paraná. Costuma dizer que o Paraná é mais racista que a África. Foi então que recebeu uma proposta do seu supervisor para ser realocado em Uberlândia, que aceitou, ainda que B., A., e H. decidissem ficar em Francisco Beltrão.

$O$ trabalho de sangrador que estes imigrantes executam através dos contratos com o GAH é basicamente o mesmo, no Paraná ou em Minas Gerais. $O$ sangrador recebe um salário de por volta de 800 reais, como já dito, para abater dentro de uma norma religiosa segundo a qual, em linha de abate orientada para oeste, a ave deve ser abatida com um só golpe de faca. Uma oração a Alá deve ser proferida ao início de cada turno. Os abates são organizados em ágeis linhas de produção, de modo que cada sangrador execute 2 mil frangos por hora - ou um frango a cada dois segundos - realizando um número de movimentos que deixa qualquer técnico de Medicina do Trabalho de cabelos em pé. Os turnos são organizados em blocos de duas horas, com intervalo de descanso de trinta minutos. Uma diária de trabalho é composta por três turnos de duas horas, com dois intervalos de trinta minutos, de forma que o sangrador deve passar sete horas por dia na linha de abate, seis dias por semana.

A situação dos trabalhadores de frigorífico no Brasil foi relatada recentemente pelo vídeo-documentário Carne Osso, produzido pelo Repórter Brasil. 
No que se refere às informações que pude obter no trabalho de campo, alguns aspectos saltam aos olhos. Em entrevista realizada no Sindicato dos Trabalhadores na Indústria de Alimentação (Sintrial), do município de Dois Vizinhos, o diretor do sindicato destaca que o pior aspecto das relações de trabalho nos frigoríficos é de ordem sanitária.

$O$ trabalho nas linhas de abate, no desossamento de frangos, embalagem, entre outros, acarreta graves danos à saúde do trabalhador. As lesões por esforço, ao mesmo tempo em que passaram a ser uma regra geral, inclusive contabilizada nas planilhas de gestão de Recursos Humanos, não encontram nenhum anteparo no plano da saúde pública. Os municípios de Francisco Beltrão e Dois Vizinhos, por exemplo, não contam com nenhuma clínica de fisioterapia que possa iniciar algum tipo de tratamento médico das doenças causadas pelo trabalho, ainda que seja de conhecimento geral que lesões dessa natureza são de caráter crônico, ou seja, os braços desses trabalhadores ficarão lesados para o resto de suas vidas. Assim, quando um sangrador de frangos apresenta uma lesão, seu supervisor concede-lhe uma licença não remunerada de um mês, às vezes dois meses. Tudo o que o sangrador pode fazer é descansar um pouco os braços, com a promessa de que possa voltar a sacrificá-los de novo assim que a dor da lesão voltar a ser suportável ou que a sua reprodução social esteja posta em cheque de tal maneira que ele se sujeite mesmo com a lesão inflamada.

Tal conjunto geral de relações, já plenamente inaceitável, é composto ainda pelo sórdido detalhe de que os sangradores são submetidos a regimes de trabalho temporário, de forma que os períodos de trabalho coincidam com o prazo de três meses - período em que seu documento de residência provisório no país tem validade. Quando esse período se encerra, o trabalhador tem que renovar o contrato de trabalho e assim se submeter a um novo exame médico de admissão. Um trabalhador que tenha sido destroçado pelo trabalho de sangrador na última temporada, provavelmente será descartado e declarado inapto pelo médico do trabalho do frigorífico.

A relação do GAH com os frigoríficos também flerta com uma reprodução que trilha a penumbra social. $O$ trabalho de sangrador é uma atividade-fim de um frigorífico e, portanto, de acordo com a legislação trabalhista não pode sofrer terceirização. Ao longo de 2010 vários frigoríficos da Sadia foram lacrados pela Justiça, em função de processos do Ministério Público, a partir de denúncias sobre a terceirização de atividades-fim. A pressão dos industriais sobre o Ministério Público foi tal que logo as linhas voltaram a correr e o processo arquivado.

De acordo com dados oferecidos pelo Sintrial-PR, alguns processos foram movidos por sangradores de frangos da seção halal contra a Sadia. As denúncias contra a Sadia afirmam que os sangradores são obrigados a cumprir segundo e terceiro turnos não remunerados, o que caracterizaria trabalho análogo ao escravo. Em um dos casos que tivemos acesso no Tribunal Regional do Trabalho do Paraná (9a Região), um processo movido por um sangrador de frangos do 
Congo obrigou a Sadia a pagar uma indenização coletiva aos trabalhadores da planta de Francisco Beltrão. Tal indenização não garantiu, entretanto, que essa prática tenha sido imediatamente coibida, uma vez que o próprio $\mathrm{H}$. tenha relatado que os sangradores são obrigados a prolongar seus turnos de acordo com a necessidade de produção da fábrica, sem receberem por isso.

Como o GAH monopoliza o fornecimento de trabalhadores para a sangria de frangos para todos os frigoríficos do Brasil, os cerca de quinhentos sangradores halal são submetidos a esse mesmo regime de trabalho.

Já os moradores de Francisco Beltrão pouco sabem a respeito "dos africanos que começaram a aparecer por aqui". Em entrevistas realizadas com funcionários da Sadia, eles demonstram preocupação com a compra da Sadia pela Perdigão, que trouxe a demissão, realocação e diminuição de salários de centenas de funcionários, para adequar o sistema produtivo aos programas de flexibilidade da atual BRFoods.

De toda forma, esse conjunto de relações constatadas na pesquisa demonstra a contradição da própria mobilidade do trabalho (GAUDEMAR, 1977) uma vez que tais sujeitos encontrar-se-iam em uma encruzilhada: postos em sociabilidade, pela expropriação de seus meios de produção, no mundo monetarizado da moderna mercadoria, ao mesmo tempo em que o próprio liberalismo do mercado passa a ser acessado positivamente por eles, enquanto possibilidade de escolha da relação à qual poderão se sujeitar. Como não poderia deixar de ser, as escolhas feitas pelo sujeito, em uma sociedade que universaliza o totalitarismo da mercadoria, são determinadas pelas ofertas postas pelo próprio mercado.

I., H., B. e A. fugiram da Guiné a partir de um conjunto de estratégias, como o financiamento de passagens aéreas com dinheiro de um partido político ou com grana emprestada de alguém na família, ou ainda às escondidas em porões de navios. Esse fato é importante para pensarmos adiante sobre a falta de autonomia da explicação cultural e o caráter político e instrumental que o Estatuto de Refugiado cumpre, ao separar os imigrantes políticos dos econômicos. Não seria o refugiado um imigrante da crise capitalista? Vamos lidar com essas questões a seguir.

\section{Diante da Lei: o solicitante de refúgio}

O outro lado do problema que apresentamos pode ser referido como a dimensão jurídica do imigrante. Partindo-se das estratégias que os próprios imigrantes africanos têm acionado, encontramos um conjunto majoritário de indivíduos em busca do status de refugiado.

Apesar da informação ser amplamente divulgada e conhecida do público leitor de Travessia, reapresentaremos a definição do Estatuto do Refugiado com a intenção de problematizá-la a partir da nossa pesquisa. 
I., H., B., e A, durante a curta estada que tiveram na Casa do Migrante, travaram contato com outros rapazes que estavam em processo de solicitação de refúgio. Aos poucos foram tomando conhecimento dos meandros institucionais e decidiram solicitar o status de refugiado. Para colocar esse processo em andamento, a primeira providência que tomaram foi realizar uma visita ao centro de acolhida para refugiados da Cáritas Arquidiocesana em São Paulo em parceria com o ACNUR-ONU (Alto Comissariado das Nações Unidas para Refugiados da Organização das Nações Unidas), a poucos metros da Praça da Sé. Lá foram alvo de uma entrevista razoavelmente detalhada sobre suas trajetórias. Os funcionários do centro dão início a um processo de solicitação de refúgio junto ao CONARE (Comitê Nacional para os Refugiados), órgão colegiado, vinculado ao Ministério da Justiça, que integra, além de representantes de uma série de ministérios, a Polícia Federal, ONGs do setor, Cáritas Arquidiocesana e o próprio ACNUR.

Cada um do grupo sai do posto com um documento provisório, referente ao processo de solicitação de refúgio que será analisado nos próximos três meses. Com o protocolo em mãos, podem solicitar uma carteira de trabalho - o documento requisitado pelo GAH para darem início ao trabalho como sangradores de frango.

Mas, enfim: o que é um refugiado? De acordo com o Estatuto do Refugiado, produzido na Convenção da ONU de 1951, são refugiados os indivíduos que se encontram fora do seu país por causa de fundado temor de perseguição por motivos de raça, religião, nacionalidade, opinião política ou participação em grupos sociais, e que não possa (ou não queira) voltar para casa. Posteriormente, foram também declarados como refugiados indivíduos que travaram contato com conflitos armados, violência generalizada e violação massiva dos direitos humanos.

No Brasil, o Estatuto da ONU foi ratificado em 1960. Em 1997, o país aprova também a Lei 9.474 que define os mecanismos que implementam o Estatuto de 1951, entre outras coisas, como a criação do CONARE e os meandros institucionais que normatizam o status de refugiado.

Como se pode depreender de uma leitura dos critérios norteadores da condição de refugiado, tal status baseia-se em uma cisão entre os critérios econômicos e os critérios políticos que mobilizam os imigrantes - mas somente se compreendemos o refugiado também como um imigrante.

A separação habitual entre imigrantes forçados e imigrantes livres existe justamente para garantir essa separação aparente entre os fenômenos que, como já demonstramos, não tem operacionalidade nenhuma, uma vez que também os imigrantes forçados traçam estratégias de mobilidade do trabalho - da compra de passagens aéreas às viagens às escuras nos porões dos navios da África atlântica, estratégias que só são possíveis porque sabem que poderão tentar vender sua força de trabalho em outro lugar. 
Entretanto, a definição de um refugiado como alguém que sofreu graves violações também não é falsa, falsa antes é a sua apresentação autonomizada para ativar um aparato de controle. Vamos ao problema.

Desde 2008, H., B., e A., vivem sob a condição de solicitante de refúgio: seus processos de solicitação para acessar o estatuto de refugiado nunca chegaram a um termo. A cada vez que seu processo é indeferido eles voltam a São Paulo para refazer o pedido de refúgio. Esse processo sem fim os coloca em uma situação de provisoriedade-permanente que serve muito bem à preservação de todo aquele jogo de relações às quais os sangradores de frango estão atados.

Caso queira-se argumentar que esse é um fato isolado à $H_{\text {., }}$ B., ou A., a apresentação dos dados sobre solicitantes de refúgio do ACNUR Brasil poderá provar que, antes disso, eles são justamente a explicitação de uma lógica geral da execução do Estatuto do Refugiado no país - ou da manutenção de imigrantes indesejados a uma condição forçada de provisoriedade.

Em 2012, o número de concessões de refúgio foi de 199, em 2013 o número cresceu para 649 (sendo que desses 283 são sírios), a soma de todos os outros (haitianos, colombianos e todos os africanos) não passa de 366. A cada semana a Casa do Migrante recebe dezenas de novos imigrantes africanos (mas não somente africanos) que iniciam o processo de solicitação de refúgio.

Entretanto, o número de solicitações de refúgio em 2012 foi de 2,1 mil e em 2013 foi de 5,2 mil. Ou seja, em 2013 apenas 9,5\% dos pedidos foram aceitos. Em 2012 apenas $12 \%$ dos pedidos foram aceitos.

O que se pode depreender desses dados? De duas opções, uma: Ou os solicitantes de refúgio são parte de um inexplicável fenômeno de mitomania em massa ou o Estatuto do Refugiado é um aparato de controle do Estado sobre o imigrante indesejado - mulheres, pobres, negros, latino-americanos - que encerra suas possibilidades de trabalho ao mais baixo escalão da sociedade através da manutenção desta condição jurídica nebulosa - o solicitante de refúgio.

A recepção do Estatuto do Refugiado no Brasil surgiu como uma solução de caráter estratégico para adequar os imigrantes indesejados a postos de trabalho subalternos, ao mesmo tempo em que suas trajetórias são controladas de perto, uma vez que o solicitante tem que se reapresentar ao Estado em um período trimestral para receber a notícia do novo indeferimento.

Essa dinâmica nos faz desconfiar que o discurso humanitário - contra as graves violações à pessoa humana - não conseguiu deixar de ser uma embalagem de um aparato coercitivo de execução da mobilidade do trabalho em crise.

Entretanto, cuidado e controle formaram um par indissociável de modo que qualquer crítica ao Estatuto do Refugiado aparece como uma recusa do cuidado em nome da crítica à submissão a tais dinâmicas sociais em crise. Antes disso, a crítica aos aparatos de controle do Estado deviam servir a uma crítica mais 
profunda das sociedades produtoras de mercadoria que do alto de sua arrogância histórica, pretendem criar um campo autônomo de resolução dos conflitos sociais na política ou na jurisprudência, como se tais campos não fossem parte intrínseca da crise da sociabilidade capitalista. Os refugiados são uma profunda expressão do trabalhador na crise.

O diretor do $\mathrm{GAH}$, em uma entrevista, relatou a seguinte história: Nas mesas de alta negociação do mercado de frangos, com um ministro de comércio de Mubaraki, no Egito, um produtor de frangos da Indonésia oferecia frangos quase ao mesmo preço que os brasileiros. 0 diretor brasileiro então argumentou: Nossos frangos são sangrados por irmãos muçulmanos refugiados das maiores e mais inimagináveis violações, dignamente acolhidos em nosso país. O ministro não pensou duas vezes e ficou com os frangos brasileiros abatidos por refugiados muçulmanos.

\section{Diante da conclusão: dois pontos para pensar}

Trabalham na Sadia de Francisco Beltrão, sob as condições aqui apresentadas, imigrantes africanos oriundos da África atlântica, principalmente Congo, Guiné, Costa do Marfim, mas também asiáticos, como nepalenses, afegãos, paquistaneses e iraquianos. Podem ser encontrados ainda paranaenses que se autodeclaram muçulmanos para conseguir um trabalho nas linhas de sangria. De forma geral, tal relação entre religião e trabalho demonstra que a religiosidade é acessada de acordo com o contexto social e a oportunidade de emprego. Para desespero de uma perspectiva dita cultural que apresenta o campo da cultura como autônomo em relação ao dito economicismo estruturalista, o que a experiência demonstra é que a religião é um atributo da mobilidade do trabalho (GAUDEMAR, 1977), acionada pelo sujeito de acordo com a circunstância de sujeição ao trabalho.

O fato de que I., H., B. e A. fugiram da Guiné - ainda que apresentado como desencadeado por conflitos de ordem étnica e cultural - não pode ser pensado fora da crise do Estado nacional guineense, esta movida pela crise de reprodução social geral da própria modernização deste território, no interior da derrocada das sociedades produtoras de mercadorias.

Por outro lado, o conhecimento empírico das relações de trabalho dos solicitantes de refúgio no Brasil explicita o outro lado das formulações cândidas acerca do dito reassentamento solidário de refugiados no país. Costumeiramente isoladas no campo jurídico, as reflexões sobre a recepção do Estatuto do Refugiado no país passam ao largo de explicitar como os aparatos jurídicos servem muito bem às relações de trabalho sobre as quais se assentam os solicitantes de refúgio. Infinitamente distante estão então da possibilidade de pensar criticamente inclusive o próprio Estatuto do Refugiado como um aparato coercitivo de controle das migrações internacionais e de adequação jurídica das 
relações de trabalho próprias do colapso do processo de modernização - ou ainda de pensar criticamente os Direitos Humanos como elemento reprodutor da moderna sociedade produtora de mercadoria em derrocada (KURZ, 2003).

Enfim, B., H. e A. continuam trabalhando como sangradores de frango em Francisco Beltrão, aguardando o próximo indeferimento no processo de refúgio para renovarem o contrato na Sadia. I. encontrou uma companheira, se casou, teve uma filha e conseguiu um documento de residência permanente no Brasil. Agora está desempregado.

Em seu livro $O$ processo, Kafka apresenta uma parábola, contada pelo capelão do presídio ao personagem Joseph K., publicada em separado, com o título de Diante da Lei. Nessa estória, um camponês se apresenta diante da porta da Lei. Protegendo a porta reside um guarda, a quem o camponês pergunta se pode entrar, já que a porta está aberta. $O$ guarda diz que não. $O$ camponês pensa e pergunta se algum dia poderá entrar. O guarda diz que é possível, mas agora não. $O$ camponês passa toda a sua vida sentado em frente à porta da Lei. $O$ guarda aceita até um suborno, para provar que não estaria fazendo tudo que estava a seu alcance. $O$ camponês começa a conversar com as pulgas em seu pescoço, pedindo que o guarda Ihe deixe passar. Já agonizando, pergunta finalmente ao guarda: Eu só não entendo uma coisa. Todo esse tempo eu permaneci aqui na porta da Lei e ninguém tentou entrar? Então o guarda responde: Esta porta foi feita para você - e somente para você. Agora que você vai morrer eu vou fechá-la.

A ameaça é clara: o solicitante de refúgio terá direito a uma pasta somente sua em uma gaveta, em alguma estante, em algum andar de algum prédio em alguma cidade. A cada três meses o guarda responde: Agora não!

\section{Referências}

GAUDEMAR, Jean Paul de. A mobilidade do trabalho e a acumulação capitalista. Lisboa: Estampa, 1977.

KAFKA, Franz. O processo. Tradução Modesto Carone. São Paulo: Companhia das Letras, 1988. KURZ, Robert. Os paradoxos dos direitos humanos. Inclusão e exclusão na modernidade. In: Folha de São Paulo, 16 de março de 2003. Tradução de Luis Repa.

SILVA, Allan Rodrigo de Campos. Imigrantes afro-islâmicos na indústria avícola halal brasileira. Dissertação de mestrado em Geografia Humana, São Paulo, FFLCH-USP, 2013.

\section{RESUMO}

O artigo enfoca o caso de imigrantes africanos que são solicitantes de refúgio e trabalham como sangradores de frangos em uma rede de frigoríficos no Brasil. Suas trajetórias apresentam graves violações de direitos, com envolvimento em relações de trabalho degradantes, ligadas a uma condição jurídica que os mantém presos a uma situação de provisoriedade permanente, como eternos solicitantes de refúgio.

Palavras-Chave: imigração africana; solicitantes de refúgio; mobilidade do trabalho. 


\begin{abstract}
The article focuses on the case of African immigrants who are asylum seekers and work as chicken slaughterers in Brazilian meat processing units. Their trajectories point to serious rights violations, related to their labor relations, linked to a legal status that keeps them trapped in a situation of permanent temporariness, as eternal asylum seekers.
\end{abstract}

Keywords: african immigration; asylum seekers; labor mobility. 